\title{
From pluripotency to myogenesis: a multistep process in the dish
}

\author{
Barbara Świerczek $^{1} \cdot$ Maria A. Ciemerych ${ }^{1} \cdot$ Karolina Archacka $^{1}$
}

Received: 14 July 2015/Accepted: 30 November 2015/Published online: 29 December 2015

(C) Springer International Publishing Switzerland 2015

\begin{abstract}
Pluripotent stem cells (PSCs), such as embryonic stem cells or induced pluripotent stem cells are a promising source of cells for regenerative medicine as they can differentiate into all cell types building a mammalian body. However, protocols leading to efficient and safe in vitro generation of desired cell types must be perfected before PSCs can be used in cell therapies or tissue engineering. In vivo, i.e. in developing mouse embryo or teratoma, PSCs can differentiate into skeletal muscle, but in vitro their spontaneous differentiation into myogenic cells is inefficient. Numerous attempts have been undertaken to enhance this process. Many of them involved mimicking the interactions occurring during embryonic myogenesis. The key regulators of embryonic myogenesis, such as Wnts proteins, fibroblast growth factor 2 , and retinoic acid, have been tested to improve the frequency of in vitro myogenic differentiation of PSCs. This review summarizes the current state of the art, comparing spontaneous and directed myogenic differentiation of PSCs as well as the protocols developed this far to facilitate this process.
\end{abstract}

Keywords Pluripotent stem cells · Spontaneous differentiation · Directed differentiation - Skeletal muscle · Myogenesis $\cdot$ Regenerative medicine

Karolina Archacka

kczaja@biol.uw.edu.pl

1 Department of Cytology, Faculty of Biology, University of Warsaw, Miecznikowa 1, 02-096 Warsaw, Poland

\section{Introduction}

Pluripotent stem cells (PSCs) are a valuable potential source of various cell types for regenerative medicine as they are able to differentiate into all cell types building a mammalian body. Importantly, PSCs can be easily expanded in vitro and have the capacity to undergo unlimited cell divisions, retaining their pluripotency. Among currently available PSCs are embryonic carcinoma cells (ECCs; Kahan and Ephrussi 1970; Rosenthal et al. 1970); embryonic stem cells (ESCs; Evans and Kaufman 1981; Martin 1981), epiblast stem cells (EpiSCs; Brons et al. 2007), recently derived region specific epiblast stem cells (rsEpiSCs; Wu et al. 2015), and induced pluripotent stem cells (iPSCs; Takahashi and Yamanaka 2006). However, only ESCs and iPSCs are considered as candidates for therapeutic approaches. For many years ESCs were derived from the inner cell mass of blastocysts, i.e. at 3.5 day of mammalian development, a process that inevitably leads to embryo destruction. For this reason ESCs sparked public discussion and ethical controversy, putting in question their potential use in regenerative medicine. However, in 2006 a new method of ESC derivation was proposed by Klimanskaya and co-workers, who used a single blastomere isolated from the embryo without disturbing further development (Klimanskaya et al. 2006). At the same time, the ground-breaking experiments involving overexpression of Oct4, Sox2, Klf4, and c-myc in mouse and human fibroblasts led to the generation of the first iPSCs, giving the opportunity for PSC derivation from non-embryonic (i.e. fetal or adult) cells (Takahashi and Yamanaka 2006; Takahashi et al. 2007). In recent years, significant progress in iPSC technology has been made, enabling reprogramming of different somatic cells to a pluripotent state in a safe way, i.e. using non-viral and 
transgene-free methods (for review see Lin and Wu 2015; Seki and Fukuda 2015). Along with the already mentioned methods of ESC derivation, these achievements resurrected the expectations for use of PSCs in regenerative medicine. In February

2015 Schwartz and co-workers summarized the results of a first clinical trial during which PSC-derivatives were used. During experimental therapy, patients suffering from either age-related macular degeneration (Clinical Trials.gov NCT01344993) or Stargardt's macular dystrophy (ClinicalTrials.gov NCT01345006) received subretinal injections of retinal pigment epithelium cells derived from human ESCs. Twenty-two months of follow up revealed that visual acuity improved significantly in 10 of 18 patients and to a lesser extent in the next seven patients (Schwartz et al. 2012). Currently, several other clinical trials based on PSC transplantation are ongoing (ClinicalTrials.gov; for review see Kimbrel and Lanza 2015). Thus, application of PSC-derivatives in regenerative medicine can be achieved.

Spontaneous multidirectional differentiation of PSCs occurs in vivo, e.g. when these cells are injected into morula or blastocyst, they contribute to all tissues in the formed chimera (for review see Tarkowski 1998). Derivatives of all three germ layers can also be found in teratomas formed by differentiating PSCs after their transplantation either into immunologically privileged sites such as kidney capsule or testis or under the skin of immunodeficient mouse recipients (for review see Grabowska et al. 2012a). In vitro PSC differentiation can be induced by their culture in suspension what leads to the formation of so called embryoid bodies (EBs), three-dimensional aggregates in which cells differentiate into three germ layers: ecto-, endo-, and mesoderm. When placed in culture dishes, EBs adhere and form outgrowths composed of different types of differentiating cells. Under such conditions some cell types, such as cardiomyocytes or neurons, were shown to arise with high frequency while others, for example skeletal myoblasts, are rare (for review see Guan et al. 1999; Grivennikov 2008; Murry and Keller 2008). Since efficient generation of myogenic cells is essential for designing cell therapies for dysfunctional muscles, many attempts have been made to improve techniques of PSC myogenic differentiation.

Skeletal muscle has the ability to regenerate after injuries occurring as a result of intense physical training or development/progression of skeletal muscle diseases, such as muscular dystrophies (e.g. Duchenne muscular dystrophy, DMD). This ability relies on the presence of satellite cells, i.e. muscle specific stem cells which differentiate to skeletal myoblasts (for review see Moraczewski et al. 2008; Scharner and Zammit 2011; Yablonka-Reuveni
2011). Differentiation and fusion of myoblasts lead to the formation of multinucleated myotubes, and finally myofibers, reconstructing skeletal muscle. Importantly, due to their ability to self-renew, the population of satellite cells becomes restored in regenerated muscle. However, in the case of reoccurring muscle injuries observed during progression of muscular dystrophies, satellite cells fail to efficiently renew their population as they are constantly activated and undergo repeating divisions without the gaps necessary to return to the quiescent stem cells state (for review see Ciemerych et al. 2011). This eventually leads to the exhaustion of the satellite cells population, which can also occur as a result of substantial tissue loss after tumor recession. Regardless of the original cause, the depletion of satellite cells results in the impairment of muscle structure and functionality, leading to physical disability and respiratory failure which can be fatal for patients.

Transplantation of cells that could support or replace satellite cells is being considered as a cell therapy for dysfunctional skeletal muscles. Pioneering experiments involved satellite cells and myoblasts derived from them. Due to the low number of satellite cells as well as difficulties in their isolation and propagation in vitro this approach turned out to be an inefficient solution. Moreover, results of clinical trials involving myoblast transplantations in patients suffering from muscular dystrophies were unsatisfactory because of poor survival and migration of transplanted cells within the recipient tissue (for review see Bajek et al. 2015; Partridge and Morgan 2014). Therefore other sources of cells, including PSCs, have been considered for cell therapy of skeletal muscles. PSCs are a promising choice for such therapy not only because of their ability to differentiate into myogenic cells, but also due to their high proliferation potential. Skeletal muscle is the most abundant human tissue so successful cell therapy for disorders affecting all muscles will require large number of cells for transplantation.

\section{Spontaneous versus directed myogenic differentiation of PSCs}

During embryo development or teratoma formation, PSCs generate skeletal muscle, which means that they have myogenic potential. In 1994 Rohwedel and co-workers obtained the first in vitro PSCs-derived cells characterized by the expression of muscle regulatory factors (MRFs), which are transcription factors that play a key role in establishing the identity of myogenic cells as discussed below. Cells expressing MRFs, i.e. Myf5, MyoD, and myogenin were identified in 7-day-old outgrowths obtained from EBs 
formed by differentiating mouse ESCs (Rohwedel et al. 1994). However, subsequent studies revealed that myogenic markers such as MyoD or myogenin are expressed at very low level in ESCs, even after 10 days of their differentiation in EBs (Darabi et al. 2008). Abundant numbers of functional skeletal myoblasts were obtained only when forced expression of essential myogenic genes such as $\operatorname{Pax} 3$ or $\operatorname{Pax} 7$ was induced in mouse ESCs or iPSCs (Darabi et al. 2008, 2011a, b).

Pax3 and Pax7 genes are crucial for proper skeletal muscle formation during embryogenesis (for review see Buckingham and Rigby 2014). This multistep process involves inter alia generation of skeletal muscle precursor cells, their conversion into myoblasts, which then differentiate and fuse, forming the multinucleated myofibers, serving as a basic structural and functional skeletal muscle unit. In mouse embryo, which serves as a model of mammalian development, myogenesis is initiated at the 8th day of development (Fig. 1). At this time paraxial mesoderm, localized along axial structures of the embryo such as notochord and neural tube, divides into segments called somites. Next, two compartments are formed: the sclerotome, which serves as a source of embryo cartilage and bone, and the dermomyotome from which the smooth muscles, blood vessels, derm, and muscles of the body originate (Fig. 1). Generation and differentiation of somites is controlled by morphogens released by the structures adjacent to the somites. The notochord produces Sonic hedgehog (Shh), the neural tube and surface ectoderm secrete Wnts proteins and lateral mesoderm synthesizes bone morphogenetic protein 4 (BMP-4). These factors, together with fibroblast growth factor (FGF) and retinoic acid (RA) establish polarity and pattering of the somites (for review see Aulehla and Pourquie 2010; Bentzinger et al. 2012). While the dermomyotome serves as a source of trunk and limb muscles, the head muscles originate from cranial mesoderm (for review see Comai and Tajbakhsh 2014). In the early stage of embryonic myogenesis the first committed myogenic cells originating from the lips of the dermomyotome form the primitive structure called myotome. Next, in the central part of the dermomyotome, cells expressing Pax3 and $P a x 7$ appear. Since these cells extensively proliferate and serve as a source of both myoblasts and satellite cells, they are called muscle precursor cells (MPCs; Fig. 1). Although formation of muscles in different anatomical

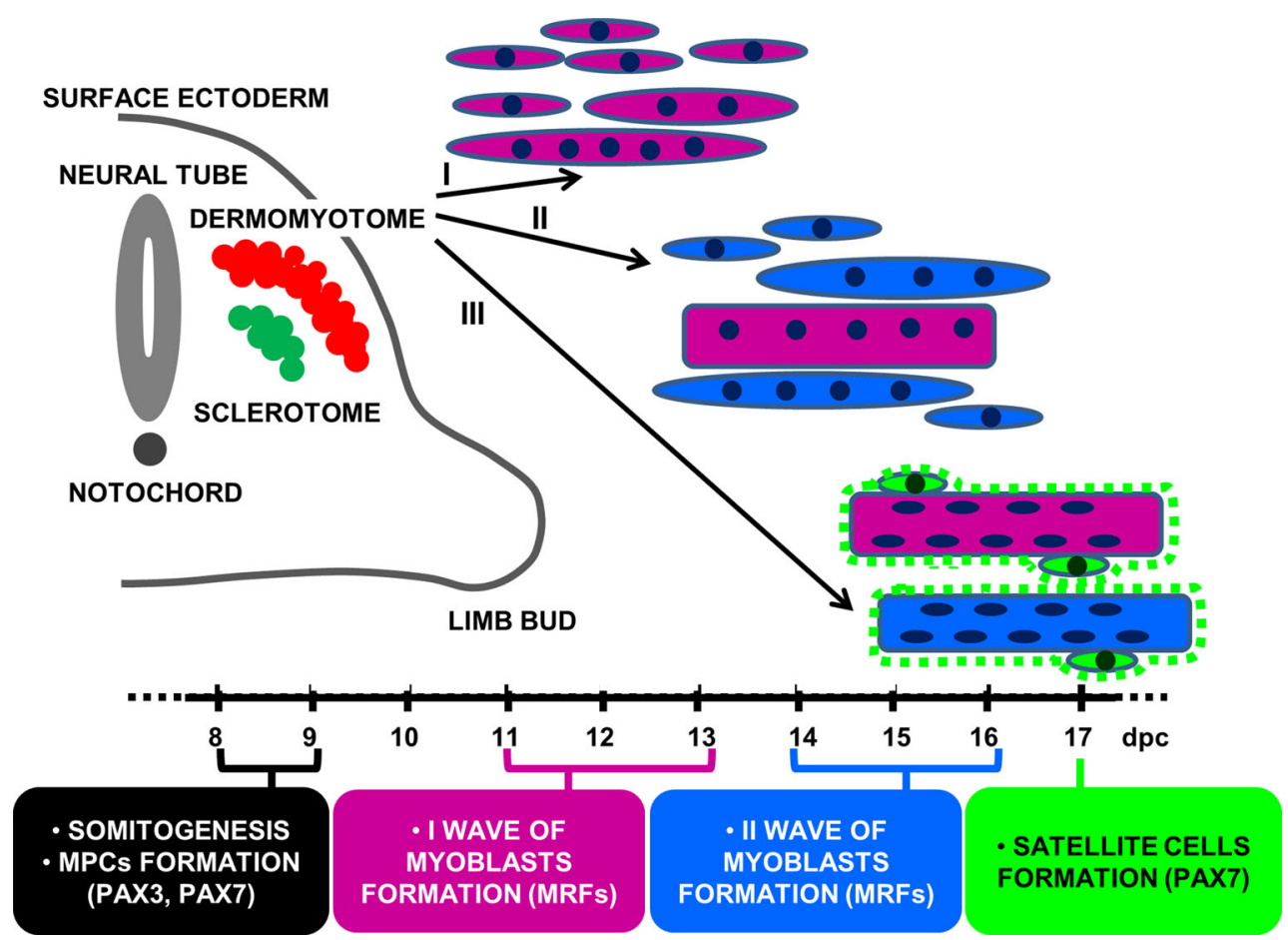

Fig. 1 Outline of myogenesis in the mouse embryo. During embryogenesis, skeletal muscles are formed from paraxial mesoderm which divides into somites, i.e. mesodermal cell aggregates localized along the axial structures of the embryo such as neural tube and notochord. Somites differentiate into dermomyotome and sclerotome. Dermomyotome serves as a source of cells producing dermis and skeletal muscle while elements of the embryo skeleton develop from the sclerotome. Muscle precursor cells (MPCs) appear in the central part of the dermomyotome. Next, two waves of myoblasts formation occur (marked I and II). Differentiation and fusion of myoblasts lead to the formation of primary (purple) and secondary (blue) multinucleated myotubes and myofibers. Eventually, at the 17th day of development, satellite cells (green)—skeletal muscle stem cellsappear in skeletal muscle (marked III). Selected stages of embryonic myogenesis and the key myogenic regulators are indicated in the boxes under the timeline (dpc-days post coitum) 
regions of the embryo (i.e. head, trunk, limbs) is controlled by different sets of genes (for review see Comai and Tajbakhsh 2014), Pax3 and $\operatorname{Pax} 7$ act as critical upstream regulators of trunk and limb muscle development, as manifested by the phenotype of double Pax3/Pax7 knockout mice lacking these muscles (Relaix et al. 2005; KassarDuchossoy et al. 2005). Pax 3 is also critical for migration of MPCs from the somites to more distant sites of myogenesis such as diaphragm, tongue, and limb buds (Bober et al. 1994; Goulding et al. 1994; Relaix et al. 2004). Moreover, it has been shown that Pax genes are essential for cell survival and proliferation during embryonic myogenesis (for review see Borycki and Emerson 1997; Relaix et al. 2004). The key role of Pax genes in myogenesis is also supported by the fact that these transcription factors direct cells into the myogenic program, acting as upstream regulators of MRFs. It has been shown that Pax 3 directly activates expression of Myf-5 in somites and limbs (Bajard et al. 2006; Himeda et al. 2013; Sato et al. 2010; Tajbakhsh et al. 1997) and promotes expression of MyoD via Pitx2 (L'Honore et al. 2010)

During embryonic myogenesis MRFs, i.e. Myf-5, MyoD, Mrf4, and myogenin, are expressed under strict temporal and spatial control. Key findings on MRFs came from knock-out mice analysis that revealed hierarchical relationship between these factors as well as differences in the specific roles they play during myogensis (for review see Comai and Tajbakhsh 2014). Myf-5, MyoD, and Mrf4 were shown to act as determination genes promoting progression of MPCs to myoblasts. Individually, these MRFs can partially compensate for defects in the other MRFs as single knock-out mice were characterized only by delay in this process while triple mutants completely lacked any myoblasts and myofibers (Braun et al. 1992; Rudnicki et al. 1993; Tajbakhsh et al. 1997; Kassar-Duchossoy et al. 2004). The last of MRFs-myogenin - acts downstream of the other MRFs and plays a unique role in driving terminal differentiation of myoblasts into myotubes and myofibers (Hasty et al. 1993; Nabeshima et al. 1993; Venuti et al. 1995). As a result of MRF activity, muscle specific microRNAs (Sweetman et al. 2008; Rao et al. 2006) or muscle specific genes such as myosin (Asakura et al. 1993) are activated, establishing the proper architecture and functionality of skeletal muscle. Last but not least, at approximately the 17th day of development, basal lamina envelops myofibers making the satellite cells accompanying each myofiber visible for the first time (Fig. 1). As men tioned before, satellite cells serve as a source of myoblasts in growing and regenerating muscle. Their role as the long-term muscle stem cells population is maintained by Pax7 which prevents the premature differentiation and exhaustion of these cells in juvenile and adult muscles (for review see Buckingham and Rigby 2014; Comai and Tajbakhsh 2014).

Spontaneous in vitro differentiation of PSCs into myogenic cells occurs at an extremely low frequency (for review see Grabowska et al. 2012a). However, various approaches to enhance PSC differentiation have been tested. As mentioned above, overexpression of key myogenic regulators such as $\operatorname{Pax} 3$ or $\operatorname{Pax} 7$ led to the efficient differentiation of PSCs into myogenic cells (Darabi et al. 2008, 2011a, b). In all of these studies PSCs (overexpressing $\operatorname{Pax} 3$ or $\operatorname{Pax} 7$ ) were first differentiated in EBs and then cultured in the outgrowths. Cells expressing PDGF $\alpha$ R, the marker of the paraxial mesoderm, and negative for Flk1, the marker of lateral plate mesoderm which serves as a source of hematopoietic cells (Sakurai et al. 2006), were FACS sorted after 5 days of EB culture. After additional 7 days of culture, cells were able not only to express MRFs and other muscle specific proteins such as Pax7 and myosin heavy chains (MyHC), but most of them (from $78 \%$ to $84 \%$, depending on the study) fused and formed multinucleated myotubes (Darabi et al. 2008, 2011a, b). Since proper development of skeletal muscle as well as their postnatal growth and regeneration depend on ability of myoblasts to fuse with each other (for review see Abmayr and Pavlath 2012), this feature is key for the functionality of myogenic cells. Even more importantly, cells positive for PDGF $\alpha \mathrm{R}$ and negative for Flk1 were also functional in vivo. When transplanted to injured or dystrophic muscle they were able to participate in muscle reconstruction as well as to settle the satellite cell niche, which is prerequisite for long-term and successful cellular therapy for dysfunctional skeletal muscles. Functionality of transplanted cells was also confirmed by the improvement of contractile properties of the muscles injected with cells (Darabi et al. 2008, 2011a, b). Finally, the therapeutic value of PSC-derived myogenic cells was underlined by their ability to settle injured muscle not only after intramuscular injection, but also after systemic transplantation (Darabi et al. 2008, 2011b). This is of great importance as many skeletal muscle diseases affect the entire body so the ability of systemically transplanted cells to migrate and settle in different groups of muscles is important to obtain therapeutic effect. However, it should be noted that although studies by Darabi and co-workers undeniably showed that PSCs can be efficiently converted into functional myogenic cells, genetically modified cells can be used in skeletal muscle disease therapy only if they are clinically safe, i.e. the integrity of their genome is preserved. To achieve this, genetic cell modification must be achieved by integration-free methods or targeted 
genome editing followed by the precise assessment of cellular genome stability. Another approach to induce differentiation of PSCs into desired cell type relies on the application of proper environmental cues. This can be achieved inter alia by the culture of PSCs in the presence of tissue specific cells or in media supplemented with factors involved in in vivo development (for review see Cohen and Melton 2011). For example, the culture of human ESCs in the presence of keratinocyte growth factor (KGF), hedgehog signaling inhibitor, and RA led to the their efficient differentiation into functional insulin producing $\beta$-pancreatic cells (Pagliuca et al. 2014). Activation of the Wnt signaling pathway followed by the culture of cells in medium supplemented with L-ascorbic acid 2-phosphate resulted in the efficient generation of cardiomyocytes (Burridge et al. 2014). Numerous attempts have been also undertaken to promote myogenic differentiation of PSCs. They involved co-culture, differentiation in EBs, and monolayer-based experiments.

\section{Co-culture-based methods of PSC myogenic differentiation}

Certain types of stem cells can be induced to undergo myogenic differentiation when cultured in the presence of myoblasts or in myoblasts-conditioned medium. This myogenic induction have been shown for mesenchymal stem cells derived from adipose tissue (Di Rocco et al. 2006; Vieira et al. 2008), mesenchymal stem cells isolated from umbilical cord connective tissue, i.e. Wharton's jelly (Grabowska et al. 2012b), and cells expressing AC133 isolated from peripheral blood (Torrente et al. 2004). All these cells were able to fuse with differentiating myoblasts and form hybrid myotubes, although with different frequencies: adipose-derived stem cells- $0.2 \%$ (Di Rocco et al. 2006), AC133 expressing cells-0.3\% (Torrente et al. 2004), and Wharton's jelly mesenchymal stem cells-15\% (Grabowska et al. 2012b). Interestingly, adipose-derived stem cells were also shown to be able to undergo fusion-independent myogenic differentiation as revealed by the expression of Pax 7 and MRFs (Di Rocco et al. 2006). Thus, factors present in media used for myoblasts culture or conditioned by myoblasts are sufficient to promote expression of muscle specific factors in these cells (Di Rocco et al. 2006; Vieira et al. 2008). In addition, AC133 expressing cells could be induced to express MRFs and form myotubes when cultured in the presence of fibroblasts secreting Wnt7a, a factor controlling myogenesis (Torrente et al. 2004).

As far as PSCs are concerned, analysis of mouse ESCs showed that when co-cultured with myoblasts, they participated in the formation of hybrid myotubes with $1 \%$ frequency
(Archacka et al. 2014). However, ESCs were not able to undergo myogenic differentiation in a fusion-independent way. MRFs were found only in the nuclei of ESCs which fused with myoblasts, but not in those cells only exposed to myoblast-conditioned medium (Archacka et al. 2014). The presence of MyoD in the nuclei of ESCs cultured in the myoblast-conditioned medium was reported only when these cells were first induced to undergo differentiation by long term co-culture with mouse OP9 stromal cells (Barberi et al. 2005). After 40 days of culture, $5 \%$ of cells expressed CD73, a marker of mesenchymal stem cells and paraxial mesoderm, i.e. the source of skeletal muscle during embryogenesis (see Fig. 1). Approximately $10 \%$ of these cells were also able to participate in the formation of hybrid myotubes when co-cultured with myoblasts (Barberi et al. 2005). Efficient differentiation of ESCs into mesoderm cells was achieved only when ESCs were co-cultured with other mouse stromal cell line-PA6 (Udagawa et al. 1989) in medium supplemented with RA and BMP-4 (Torres et al. 2012). As mentioned before, both factors are engaged in embryonic myogenesis. RA is involved in patterning of the somites (Sirbu and Duester 2006) while BMP-4 promotes expansion of MPCs in dermomyotome by delaying MRF expression (Pourquie et al. 1995). The culture of mouse ESCs in the presence of RA, BMP-4, and PA6 cells led to the generation of cells expressing the myogenic marker-desmin (Torres et al. 2012). However, expression of MRFs was not detected in cells obtained using such experimental approaches (Torres et al. 2012).

Examples presented above show that PSCs are able to undergo myogenic conversion only in fusion-dependent manner (Archacka et al. 2014) or after initial differentiation induced by stromal cell lines and/or myogenic regulators, such as Wnt7a, BMP-4, and RA (Barberi et al. 2005; Torres et al. 2012). Differences between PSCs and adipose-derived stem cells or AC133 expressing cells, i.e. those that are able to undergo myogenic differentiation in a fusion-independent way, may reflect the fact that the latter cells already express several myogenic markers-for example Pax7 and Myf-5 (Torrente et al. 2004; Di Rocco et al. 2006; Vieira et al. 2008). It should be also noted that regenerative potential of ESCs co-cultured with myoblasts was shown to be low. Bhagavati and $\mathrm{Xu}$ performed the experiment during which ESCs expressing GFP were transplanted into the muscle of $m d x$ (murine $\mathrm{X}$-linked dystrophy) mice which lack dystrophin, one of the structural proteins necessary for proper functioning of skeletal muscle (Sicinski et al. 1989). GFP and dystrophinpositive fibers were detected in the muscles of only two out of eight mice transplated with cells, and one of these mice had as few as 30 of these fibers (Bhagavati and $\mathrm{Xu}$ 2005). Together, these results indicate that the co-culture system is not efficient in the induction of myogenic differentiation of 
PSCs (Barberi et al. 2005; Bhagavati and Xu 2005; Archacka et al. 2014). In addition, although the co-culture system yields important information about myogenic potential of stem cells and reciprocal interactions between co-cultured cells, this method is not likely to be clinically suitable. Many factors influencing stem cells which are present in the medium or are released by cells co-cultured with stem cells remain unknown. Identification of factors that could direct differentiation of PSCs into functional muscle cells is necessary for clinical implementation of skeletal muscle cell therapy. This is a very challenging aim as there are many potential inducers of stem cell myogenic differentiation to be experimentally verified. Additionally, designing such protocols requires precise determination of proper doses and incubation time. Moreover, animal and human PSCs most certainly will differ in their response to selected factors (for review see Suwinska and Ciemerych 2011). Finally, PSCs propagated as EBs or cultured in monolayer may also significantly vary (Osafune et al. 2008). Despite these obstacles, numerous growth factors, cytokines, and small molecules have already been tested in both EBs and monolayer-based PSC culture systems.

\section{EB-based methods for myogenic differentiation of PSCs}

Within the first 3 days of differentiation, PSCs propagated as EBs form three germ layers. The presence of ectoderm is manifested by the expression of fibroblast growth factor 5 (FGF-5), endoderm by GATA-4, and mesoderm by Brachyury (Leahy et al. 1999). Ryan and co-workers showed that in EBs derived from human ESCs, factors characteristic for MPCs such as Meox1, Pax3, and Pax7 can be detected approximately at 8th day of culture while MRFs appear much later, i.e. after 39 days of culture (Ryan et al. 2012). In a pioneering study by Rohwedel and co-workers, MRF expression was detected in mouse ESCs after 10 days of their differentiation within EBs (Rohwedel et al 1994). However, Darabi et al. showed that level of Pax3, Pax7, and MRF expression was extremely low in human ESC-derived EBs even after 10 days of differentiation (Darabi et al. 2008). Despite these differences between experiments, the EB system was used in many studies, including those describing derivation of the first myogenic cells from mouse ESCs and iPSCs (Rohwedel et al. 1994; Mizuno et al. 2010) and human ESCs (Zheng et al. 2006).

In many experiments involving EBs formation, medium containing fetal bovine and/or horse serum was used (e.g. Rohwedel et al. 1994; Zheng et al. 2006; Mizuno et al. 2010). Although these studies yielded fundamental information about PSC differentiation, it is known that serum components may vary between batches and may affect cell differentiation and also hamper experimental reproducibility. Moreover, due to clinical requirements, a robust differentiation protocol should be free of any animal components which may pose a risk of contamination, with unknown and/or undetected animal pathogens (for review see Mannello and Tonti 2007; Unger et al. 2008). To overcome this problem, serum-free media containing defined components should be applied. The type of medium may have a great influence on PSC differentiation. For example, 4-day long culture of EBs in fetal bovine serum-containing medium resulted in $77 \%$ of cells expressing Mixl1, the key regulator of gastrulation which is crucial for endoderm and mesoderm formation (Hart et al. 2002; Pereira et al. 2012). Expression of this factor was absent in EBs cultured in serum-free medium, and was induced only when additional factors such as BMP4 and Wnt3a were added to the medium (Gertow et al. 2013).

An additional important issue linked to the development of the best differentiation protocol is the choice of PSC differentiation stage at which cells are characterized by the best therapeutic potential. With respect to the myogenic differentiation of PSCs, cells at different stages of differentiation, i.e. paraxial mesodermal cells, MPCs, satellite cells, and myoblasts can be produced. Myogenic cells at initial stages of differentiation, i.e. those expressing Pax3 and/or Pax7, were shown to be characterized by higher regenerative potential than cells that reached more advanced stages of differentiation and started to express MRFs (Montarras et al. 2005; Kuang et al. 2007; Rossi et al. 2010). The production of myogenic progenitors can also be enhanced by using genetic manipulation-free methods, for example by culturing of EBs obtained from either mouse or human ESCs in media containing a low RA concentration. This experimental approach led to the elevation of Meox1 and Pax3 expression (Kennedy et al. 2009; Ryan et al. 2012). Derivation of progenitor cells that were able to undergo terminal myogenic differentiation in vitro or participate in muscle regeneration in vivo was also described in other studies. Hwang and co-workers obtained cells expressing PDGF $\alpha \mathrm{R}$, the marker of paraxial mesoderm, and Awaya and colleagues generated Pax3/Pax7 expressing cells from human PSCs (Awaya et al. 2012; Hwang et al. 2013). However, in both of these experiments serum containing media and animal components were used. Nevertheless, it should be underlined that such studies provide data that were crucial for uncovering the mechanisms of PSC differentiation and for development of serum-free protocols for PSC myogenic differentiation. A representative serum-free protocol was described in 2014 by Hosoyama and co-workers (Fig. 2). Human ESCs and iPSCs were cultured in suspension, in medium supplemented with epidermal growth factor (EGF) and fibroblasts growth factor 2 (FGF-2). Under such conditions cells aggregated 


\begin{tabular}{|c|c|c|}
\hline REFERENCE & DIFFERENTIATION SCHEME & $\begin{array}{l}\text { EFFICIENCY OF } \\
\text { DIFFERENTIATION }\end{array}$ \\
\hline $\begin{array}{l}\text { Hosoyama } \\
\text { et al. (2014) } \\
\text { cells: } \\
\text { human ESCs } \\
\text { human iPSCs }\end{array}$ & 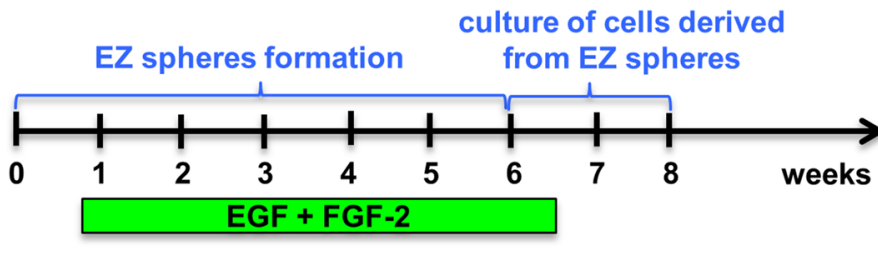 & $\begin{array}{l}\text { After } 6 \text { weeks } 20 \% \\
\text { of cells expressed } \\
\text { Pax } 7 . \text { After additional } \\
2 \text { weeks } 37 \% \text { of cells } \\
\text { expressed myogenin. } \\
\text { Cells formed } \\
\text { myotubes. }\end{array}$ \\
\hline $\begin{array}{l}\text { Xu } \\
\text { et al. (2013) } \\
\text { cells: } \\
\text { human iPSCs }\end{array}$ & $\begin{array}{l}\text { BIO + FGF-2 + forskolin } \\
2\end{array}$ & $\begin{array}{l}\text { After } 36 \text { days } 92 \% \\
\text { of cells expressed } \\
\text { myogenin and fused. } \\
\text { Cells engrafted } \\
\text { in injured muscle } \\
\text { (efficiency not } \\
\text { determined). }\end{array}$ \\
\hline $\begin{array}{l}\text { Shelton } \\
\text { et al. (2014) } \\
\text { cells: } \\
\text { mouse ESCs } \\
\text { human ESCs }\end{array}$ & 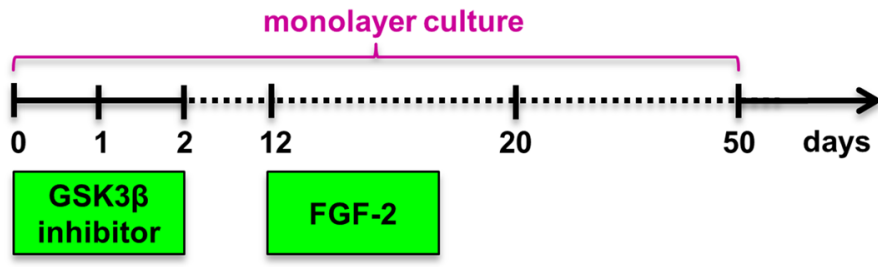 & $\begin{array}{c}\text { After } 50 \text { days } \\
\text { of culture } 43 \% \text { of cells } \\
\text { expressed Pax } 7 \text { while } \\
\text { another } 47 \% \text { of cells } \\
\text { expressed MHC. } \\
\text { MHC-positive cells } \\
\text { formed myotubes. }\end{array}$ \\
\hline $\begin{array}{c}\text { Borchin } \\
\text { et al. (2013) } \\
\text { cells: } \\
\text { human ESCs } \\
\text { human iPSCs }\end{array}$ & $\begin{array}{|llllll|} & 1 & 2 & 3 & 4 & \\
& \text { GSK3 } \beta & \text { inhibitor } & \text { FGF-2 } \\
\end{array}$ & $\begin{array}{c}\text { After } 35 \text { days } \\
\text { of culture Pax3 and } \\
\text { Pax } 7 \text { were expressed } \\
\text { in } 20 \% \text { of unsorted } \\
\text { cells and in over } 95 \% \\
\text { of cells selected by the } \\
\text { presence of c-met, } \\
\text { CXCR4, and ACHR. }\end{array}$ \\
\hline
\end{tabular}

Fig. 2 Selected methods for myogenic differentiation of PSCs. Differentiation protocols based on the propagation of PSCs in suspension (blue letters over the timelines) and in monolayer (purple letters over the timelines) are shown. Information about factors used

and formed free floating spheres, similar to EBs, but described by the authors as EZ spheres (Hosoyama et al. 2014). After 6 weeks of culture $20 \%$ of cells expressed Pax7 and were able to undergo myogenic differentiation and fuse during subsequent culture. Presence of FGF-2 was critical for derivation of myogenic progenitors since no Pax7 expressing cells were generated when this factor was omitted (Hosoyama et al. 2014). During embryonic myogenesis FGF-2 prevents the differentiation of MPCs into myoblasts, thus controlling the balance between the number of progenitor and differentiating cells (Lagha et al. 2008). Next, EGF was shown to enhance the influence of FGF-2 on differentiating PSCs. However, Hosoyama and co-workers faced a problem connected to the fact that EZ spheres, similar to EBs, are three-dimensional structures. Thus, not all of the cells within these spheres receive the signals at the same level. As a result, multiple cell types can be formed. For example, EZ spheres cultured in the for PSCs differentiation is indicated below the timelines. Cell types used in studies are listed in the left column while differentiation efficiency is described in the right column

presence of FGF-2 and EGF contained over $30 \%$ of cells expressing TuJ1, a marker of neural cells (Hosoyama et al. 2014).

In their excellent study $\mathrm{Xu}$ and co-workers examined the influence of 2400 chemicals on zebrafish myogenesis. As a result, they identified three factors, namely FGF, forskolin, and a glycogen synthase kinase $3 \beta$ (GSK3 $\beta$ ) inhibitor called BIO, which were shown to efficiently induce myogenic differentiation of human iPSC (Xu et al. 2013). As mentioned above, FGF prevents premature differentiation of MPCs during embryonic myogenesis (Lagha et al. 2008). Forskolin increases cell proliferation by activating adenylyl cyclase. GSK3 $\beta$ inhibits canonical Wnt signaling pathway by targeting its transducer, $\beta$-catenin, to degradation (for review see $\mathrm{Wu}$ and Pan 2010). As mentioned earlier Wnt signaling induces somites formation and differentiation during vertebrate myogenesis, and suppression of its activity inhibits mesoderm formation 
(Liu et al. 1999; Huelsken et al. 2000; Borello et al. 2006). Wnt signaling is also essential for development of neural tube and neural crest which provide important cues for patterning of the paraxial mesoderm (Rios et al. 2011). EBs formed from iPSCs were cultured in the presence of FGF, forskolin, and BIO for 7 days (Fig. 2). Such conditions resulted in a 200-fold increase in Pax7 expression and 60-fold induction of Myf-5 and MyoD expression, as compared to control culture conditions (Xu et al. 2013). At the same time the expression of ectoderm and endoderm markers was not changed, indicating that such conditions specifically induced myogenic differentiation of PSCs. More importantly, transplantation of the factor-treated cells into injured skeletal muscle showed that they are able to participate in mouse muscle regeneration and colonize the satellite cell niche, confirming their functionality (Xu et al. 2013).

Skeletal muscle is one of the most abundant tissues in the body. Thus, large scale cell expansion is required to generate adequate cell numbers for potential therapy or tissue engineering. Although EBs serve as a good model in basic research focused at PSC differentiation, this culture system is rather laborious and time-consuming and does not allow for generation of large quantities of differentiated cells. However, EBs can be used as an intermediate step for generation of myogenic cells from PSCs. Hwang and co-workers have shown that cells differentiated in EBs and sorted for PDGF $\alpha$ R could be successfully cultured in monolayer and retained the ability to undergo terminal myogenic differentiation despite several passages (Hwang et al. 2013). Regardless of the EB use, it is the monolayer culture that offers the possibility to generate a suitable number of cells for clinical application.

\section{Monolayer-based methods for myogenic differentiation of PSCs}

The first monolayer-based protocol for myogenic differentiation of PSCs was described by Barberi and co-workers in 2007. Human ESCs were cultured in medium supplemented with insulin, transferrin, and selenium (ITS, Barberi et al. 2007). After 35 days of culture, cells expressing CD73, a marker of mesoderm and mesenchymal stem cells, were selected. Similarly to mesenchymal stem cells originating from bone marrow or adipose tissue, the obtained CD73 expressing cells were able to undergo adipogenic, chondrogenic, and osteogenic differentiation. Moreover, up to $10 \%$ of these cells were characterized by the presence of myogenic markers such as Pax 7 and MyoD. Myogenic cells were selected from population of CD73 expressing cells on the basis of the presence of neural cell adhesion molecule (NCAM), an adhesion protein expressed by differentiating myoblasts (Walsh and Ritter 1981).
Next, culture in N2 medium, which enhances myoblasts maturation, induced NCAM expressing cells to synthesize myogenin and structural muscle proteins such as skeletal muscle actin and sarcomeric myosin, and to form myotubes (Barberi et al. 2007). This protocol did not require genetic modification, but it was lenghty and needed repetitive cell sorting. Moreover, it also involved culture in serum-containing media which was disadvantageous in terms of its future use in cell therapies.

Significant progress has been made by Sakurai and co-workers who designed a serum-free protocol resulting in the derivation of paraxial mesodermal cells, i.e. the material for further myogenic differentiation, from mouse and human ESCs and iPSCs (Sakurai et al. 2009, 2012). Differentiation of PSCs into paraxial mesodermal cells was achieved by supplementation with Activin A, a member of the TGF $\beta$ family of proteins, which prevented cell apoptosis and enhanced the expression of Brachyury and Mixl1, followed by supplementation with BMP4 that enhanced cell proliferation, and finally $\mathrm{LiCl}$. $\mathrm{LiCl}$ activated the Wnt signaling pathway and induced expression of paraxial mesoderm markers, such as Tbx6 and PDGF $\alpha$ R. Paraxial mesoderm cells obtained according to this protocol were able to undergo in vitro myogenic differentiation, manifested by the presence of myogenin and myosin heavy chain (MHC), which are markers of differentiated myoblasts, myotubes, and myofibers. Importantly, these cells also participated in muscle reconstruction in vivo (Sakurai et al. 2012).

Numerous studies have focused on the myogenic differentiation of mouse and human iPSCs (Mizuno et al. 2010; Darabi et al. 2011b; Goudenege et al. 2012; Tanaka et al. 2013; Abujarour et al. 2014; Maffioletti et al. 2015; Shoji et al. 2015). Many of these are based on MyoD overexpression, a method initially described for myogenic conversion of fibroblasts as well as neural, fat, and liver cells (Weintraub et al. 1989). Introduction of MyoD to iPSCs resulted in the derivation of myogenic cells with the efficiency as high as $90 \%$ (Goudenege et al. 2012; Tanaka et al. 2013; Abujarour et al. 2014; Maffioletti et al. 2015; Shoji et al. 2015). Availability of myogenic cells derived from human iPSCs also provides opportunity for individu alized patient therapy. However, it should be noted that in case of inherited skeletal muscle diseases such as muscular dystrophies, effective autologous cell transplantation will require genetic correction of the initial defect prior to transplantation. It has been shown that introduction of a human artificial chromosome with a complete dystrophin sequence into iPSCs derived from DMD patients or $m d x$ mice led to their successful genetic correction (Kazuki et al. 2010). Similarly, Tedesco and co-workers showed that genetic correction of iPSCs derived from patients suffering from limb-girdle muscular dystrophy $2 \mathrm{D}$ caused by mutation in the gene encoding $\alpha$-sarcoglycan can be efficiently corrected 
in vitro with a lentiviral vector carrying the gene encoding human $\alpha$-sarcoglycan (Tedesco et al. 2012). Transplantation of genetically corrected cells into $\alpha$-sarcoglycan-null mice resulted in the formation of myofibers expressing this protein (Tedesco et al. 2012). An important step towards the future treatment of muscular dystrophies using genetically corrected autologous iPSCs has been made by Filareto and co-workers. In this study iPSCs were derived from fibroblasts isolated from dystrophin and utrophin double knockout mice that are characterized by progressive muscle wasting, impaired mobility, and other symptoms resembling indicants of human DMD (Deconinck et al. 1997; Grady et al. 1997). Genetic correction of iPSCs was obtained by introduction of a micro-utrophin gene which complements the lack of both dystrophin and utrophin (Sonnemann et al. 2009) using Sleeping Beauty transposon which enables efficient and stable gene transfer with limited risk of insertional mutations (Yant et al. 2005). Next, myogenic progenitors were obtained from genetically corrected iPSCs by overexpression of Pax3 and Pax7. Transplantation of PDGF $\alpha$ R expressing cells to dystrophin and utrophin double knockout mice resulted in the restoration of dystrophin-glycoprotein complex and the improvement of muscle contractile properties. Importantly, transplanted cells were able to seed the compartment of satellite cells and participate in the subsequent regeneration of the engrafted muscle. In addition, myogenic progenitors derived from genetically corrected iPSCs were also able to migrate and engraft different muscles after systemic transplantation (Filareto et al. 2013).

Despite unquestioned achievements in the field, it is still necessary to improve existing protocols by introducing iPSCs reprogramming factors or genes promoting myogenic differentiation of PSCs with non-integrating methods, while simultaneously retaining the efficiency of cell conversion. Moreover, although genetically modified cells can currently be used as cellular models in research focused on skeletal muscle disease modelling and drug discovery, it should be noted that their differentiation may not necessarily reflect typical myogenic specification or disease development and progression. Thus, the protocols that guide the differentiation of PSCs through the key milestones of myogenesis, i.e. paraxial mesoderm formation, somitogenesis, dermomyotome development, differentiation of MPCs, myoblasts and myotubes, are desired. Recently, the protocol for PSC myogenic differentiation, recapitulating essential steps of myogenesis, has been described (Chal et al 2015). Activation of Wnt signalling followed by inhibition of BMP-4 resulted in conversion of PSCs into striated myofibers which were accompanied by Pax7-positive cells. Transplantation of Pax7-positive cells to $m d x$ mice resulted in dystrophin expression and colocalization of satellite cell niche in engrafted muscles (Chal et al 2015). Earlier, two other multi-step protocols based on embryonic myogenesis were proposed (Borchin et al. 2013; Shelton et al. 2014; Fig. 2). Both of them start with the activation of Wnt signaling as a first step to induce mesodermal differentiation of PSCs. Excellent studies by Skerjanc and co-workers revealed that the inhibition or loss of $\beta$-catenin, the main transducer of canonical Wnt signaling, decreases myogenic differentiation of PSCs (Petropoulos and Skerjanc 2002; Wong et al. 2013). Such a phenotype results from the loss of Meox1, Six1, Foxc1, Foxc2, Pax3, and Pax7, which are expressed in mesoderm, somites, and MPCs (Williams and Ordahl 1994; Reijntjes et al. 2007; Kennedy et al. 2009; Savage et al. 2010). Mouse and human ESCs cultured in the presence of GSK $\beta 3$ inhibitor, followed by FGF-2 treatment and culture in N2 medium, underwent efficient myogenic differentiation (Shelton et al. 2014; Fig. 2). Inhibition of GSK $\beta 3$ was critical for Brachyury upregulation. After 2 days of culture over $90 \%$ of differentiating ESCs expressed this mesodermal marker. Further expansion of such cells resulted in efficient specification and differentiation of myogenic cells, for example over $40 \%$ of cells expressed Pax7, a marker of MPCs, while another $47 \%$ of cells expressed MHC, a marker of differentiated myoblasts and myotubes (Shelton et al. 2014; Fig. 2). Another protocol proposed a similar approach, i.e. inhibition of GSK $\beta$ followed by FGF-2 treatment (Borchin et al. 2013; Fig. 2). Such treatment induced expression of Pax3 and Pax7 in $20 \%$ of differentiating PSCs (Borchin et al. 2013; Fig. 2). The isolation of myogenic progenitors from the whole population of differentiating PSCs was achieved on the basis of c-met and CXCR4 expression, proteins that are highly expressed during migration of MPCs within the embryo (Vasyutina et al. 2005) as well as muscle specific acetylcholine receptor (ACHR), which is required for neuromuscular junction formation (Brehm and Henderson 1988). Over $90 \%$ of cells expressing c-met, CXCR4, and ACHR synthesized Pax 3 and Pax7 and underwent myogenic differentiation as manifested by MRF expression and myotube formation (Borchin et al. 2013). Thus, two protocols based on manipulation of Wnt signaling levels and involving FGF-2 treatment led to the efficient myogenic differentiation of mouse and human ESCs as well as human iPSCs (Borchin et al. 2013; Shelton et al. 2014). However, the functionality of the obtained myogenic cells has not been tested in vivo. The question of whether these cells can give rise not only to mature myoblasts, myotubes, and myofibers, but also settle satellite cells niche remains unanswered. It is worthy to note that both protocols included chemically defined media, therefore they should be replicable and controlled. 


\section{Conclusions}

Substantial progress has been made in the development of efficient and safe protocols for myogenic differentiation of PSCs. Protocols based on knowledge concerning embryonic myogenesis provided favorable in vitro conditions for robust differentiation of PSCs into myogenic cells. How ever, there are still a few challenges, already mentioned in this review, that need to be overcome in regard to clinical application of PSC based therapy for dysfunctional skeletal muscle. Among these are: (1) elimination of any animal components used for culture and differentiation of PSCs, (2) selection of the cells characterized by the best therapeutic potential, i.e. able to efficiently migrate and engraft different groups of muscles after systemic transplantation as well as to seed the satellite cell niche and participate in subsequent regeneration of the settled muscle, (3) generation of large number of functional myogenic cells, influencing contractile properties of treated muscles, (4) derivation of clinically safe cells, characterized by genome stability after reprogramming or genetic correction. Since PSCs have the potential to form teratomas, it is very important to indicate the suitable set of markers for precise depletion of insufficiently differentiated cells and selection of clinically safe ones. Successful PSC-based therapy will also require limiting the risk of immune response to PSC derivatives. Although PSCs display some level of immuno privilege as they express low levels of major histocompatibility complex (MHC)I, lack MHCII and co-stimulatory molecules, it is currently clear that both undifferentiated ESCs and iPSCs, as well as their derivatives, can be rejected after transplantation into an immune-competent recipient (for review see Imberti et al. 2015). Experiments performed with the use of humanized mice reconstituted with a functional human immune system revealed that even in case of autologous transplantation, iPSCs can induce an immune response leading to cell rejection (Zhao et al. 2015). It is caused by elevated expression of immunogenic antigens such as Zg16 (Zhao et al. 2011). Although development of PSC-based therapy for dysfunctional skeletal muscle may still seem to be challenging, the recent achievements in the field are promising and have already led to significant progress in this protocol optimalization.

Acknowledgments The authors regret the omission of any relevant literature which may occur either because of space limitation or oversight. This study was supported by a grant funded by the Foundation for Polish Science co-financed by the European Union within European Regional Development Fund (Parent Bridge Programme, Grant Number: POMOST/2012-5/1) and by a grant from the funds of the National Science Centre allocated on the basis of the decision number DEC-2012/05/D/NZ3/02081.

\section{References}

Abmayr SM, Pavlath GK (2012) Myoblast fusion: lessons from flies and mice. Development 139(4):641-656

Abujarour R, Bennett M, Valamehr B, Lee TT, Robinson M, Robbins D, Le T, Lai K, Flynn P (2014) Myogenic differentiation of muscular dystrophy-specific induced pluripotent stem cells for use in drug discovery. Stem Cells Transl Med 3(2):149-160

Archacka K, Denkis A, Brzoska E, Swierczek B, Tarczyluk M, Janczyk-Ilach K, Ciemerych MA, Moraczewski J (2014) Competence of in vitro cultured mouse embryonic stem cells for myogenic differentiation and fusion with myoblasts. Stem Cells Dev 23(20):2455-2468

Asakura A, Fujisawa-Sehara A, Komiya T, Nabeshima Y, Nabeshima Y (1993) MyoD and myogenin act on the chicken myosin lightchain 1 gene as distinct transcriptional factors. Mol Cell Biol 13(11):7153-7162

Aulehla A, Pourquie O (2010) Signaling gradients during paraxial mesoderm development. Cold Spring Harb Perspect Biol 2(2):a000869

Awaya T, Kato T, Mizuno Y, Chang H, Niwa A, Umeda K, Nakahata T, Heike T (2012) Selective development of myogenic mesenchymal cells from human embryonic and induced pluripotent stem cells. PLoS One 7(12):e51638

Bajard L, Relaix F, Lagha M, Rocancourt D, Daubas P, Buckingham ME (2006) A novel genetic hierarchy functions during hypaxial myogenesis: Pax3 directly activates Myf5 in muscle progenitor cells in the limb. Genes Dev 20(17):2450-2464

Bajek A, Porowinska D, Kloskowski T, Brzoska E, Ciemerych MA, Drewa T (2015) Cell therapy in Duchenne muscular dystrophy treatment: clinical trials overview. Crit Rev Eukaryot Gene Expr 25(1):1-11

Barberi T, Willis LM, Socci ND, Studer L (2005) Derivation of multipotent mesenchymal precursors from human embryonic stem cells. PLoS Med 2(6):e161

Barberi T, Bradbury M, Dincer Z, Panagiotakos G, Socci ND, Studer L (2007) Derivation of engraftable skeletal myoblasts from human embryonic stem cells. Nat Med 13(5):642-648

Bentzinger CF, Wang YX, Rudnicki MA (2012) Building muscle: molecular regulation of myogenesis. Cold Spring Harb Perspect Biol 4:2

Bhagavati S, Xu W (2005) Generation of skeletal muscle from transplanted embryonic stem cells in dystrophic mice. Biochem Biophys Res Commun 333(2):644-649

Bober E, Franz T, Arnold HH, Gruss P, Tremblay P (1994) Pax-3 is required for the development of limb muscles: a possible role for the migration of dermomyotomal muscle progenitor cells. Development 120(3):603-612

Borchin B, Chen J, Barberi T (2013) Derivation and FACS-mediated purification of PAX3+/PAX7+ skeletal muscle precursors from human pluripotent stem cells. Stem Cell Rep 1(6):620-631

Borello U, Berarducci B, Murphy P, Bajard L, Buffa V, Piccolo S, Buckingham M, Cossu G (2006) The Wnt/beta-catenin pathway regulates Gli-mediated Myf5 expression during somitogenesis. Development 133(18):3723-3732

Borycki AG, Emerson CP (1997) Muscle determination: another key player in myogenesis? Curr Biol 7(10):620-623

Braun T, Rudnicki MA, Arnold HH, Jaenisch R (1992) Targeted inactivation of the muscle regulatory gene Myf-5 results in abnormal rib development and perinatal death. Cell 71(3): 369-382

Brehm P, Henderson L (1988) Regulation of acetylcholine receptor channel function during development of skeletal muscle. Dev Biol 129(1):1-11 
Brons IG, Smithers LE, Trotter MW, Rugg-Gunn P, Sun B, de Sousa Chuva, Lopes SM, Howlett SK, Clarkson A, Ahrlund-Richter L, Pedersen RA et al (2007) Derivation of pluripotent epiblast stem cells from mammalian embryos. Nature 448(7150):191-195

Buckingham M, Rigby PW (2014) Gene regulatory networks and transcriptional mechanisms that control myogenesis. Dev Cell 28(3):225-238

Burridge PW, Matsa E, Shukla P, Lin ZC, Churko JM, Ebert AD, Lan F, Diecke S, Huber B, Mordwinkin NM et al (2014) Chemically defined generation of human cardiomyocytes. Nat Methods 11(8):855-860

Chal J, Oginuma MA, Tanoury Z, Gobert B, Sumara O, Hick A, Bousson F, Zidouni Y, Mursch C, Moncuquet P, Tassy O, Vincent S, Miyanari A, Bera A, Garnier JM, Guevara G, Hestin M, Kennedy L, Hayashi S, Drayton B, Cherrier T, GayraudMorel B, Gussoni E, Relaix F, Tajbakhsh S, Pourquié O (2015) Differentiation of pluripotent stem cells to muscle fiber to model Duchenne muscular dystrophy. Nat Biotechnol 33(9):962-969

Ciemerych MA, Archacka K, Grabowska I, Przewozniak M (2011) Cell cycle regulation during proliferation and differentiation of mammalian muscle precursor cells. Results Probl Cell Differ 53:473-527

Cohen DE, Melton D (2011) Turning straw into gold: directing cell fate for regenerative medicine. Nat Rev Genet 12(4):243-252

Comai G, Tajbakhsh S (2014) Molecular and cellular regulation of skeletal myogenesis. Curr Top Dev Biol 110:1-73

Darabi R, Gehlbach K, Bachoo RM, Kamath S, Osawa M, Kamm KE, Kyba M, Perlingeiro RC (2008) Functional skeletal muscle regeneration from differentiating embryonic stem cells. Nat Med 14(2):134-143

Darabi R, Pan W, Bosnakovski D, Baik J, Kyba M, Perlingeiro RC (2011a) Functional myogenic engraftment from mouse iPS cells. Stem Cell Rev 7(4):948-957

Darabi R, Santos FN, Filareto A, Pan W, Koene R, Rudnicki MA, Kyba M, Perlingeiro RC (2011b) Assessment of the myogenic stem cell compartment following transplantation of Pax3/Pax7induced embryonic stem cell-derived progenitors. Stem Cells 29(5):777-790

Deconinck AE, Rafael JA, Skinner JA, Brown SC, Potter AC, Metzinger L, Watt DJ, Dickson JG, Tinsley JM, Davies KE (1997) Utrophin-dystrophin-deficient mice as a model for Duchenne muscular dystrophy. Cell 90(4):717-727

Di Rocco G, Iachininoto MG, Tritarelli A, Straino S, Zacheo A, Germani A, Crea F, Capogrossi MC (2006) Myogenic potential of adipose-tissue-derived cells. J Cell Sci 119(14):2945-2952

Evans MJ, Kaufman MH (1981) Establishment in culture of pluripotential cells from mouse embryos. Nature 292(5819):154-156

Filareto A, Parker S, Darabi R, Borges L, Iacovino M, Schaaf T, Mayerhofer T, Chamberlain JS, Ervasti JM, McIvor RS et al (2013) An ex vivo gene therapy approach to treat muscular dystrophy using inducible pluripotent stem cells. Nat Commun 4:1549

Gertow K, Hirst CE, Yu QC, Ng ES, Pereira LA, Davis RP, Stanley EG, Elefanty AG (2013) WNT3A promotes hematopoietic or mesenchymal differentiation from hESCs depending on the time of exposure. Stem Cell Rep 1(1):53-65

Goudenege S, Lebel C, Huot NB, Dufour C, Fujii I, Gekas J, Rousseau J, Tremblay JP (2012) Myoblasts derived from normal hESCs and dystrophic hiPSCs efficiently fuse with existing muscle fibers following transplantation. Mol Ther 20(11):2153-2167

Goulding M, Lumsden A, Paquette AJ (1994) Regulation of Pax-3 expression in the dermomyotome and its role in muscle development. Development 120(4):957-971

Grabowska I, Archacka K, Czerwinska AM, Krupa M, Ciemerych MA (2012a) Mouse and human pluripotent stem cells and the means of their myogenic differentiation. Results Probl Cell Differ 55:321-356

Grabowska I, Brzoska E, Gawrysiak A, Streminska W, Moraczewski J, Polanski Z, Hoser G, Kawiak J, Machaj EK, Pojda Z et al (2012b) Restricted myogenic potential of mesenchymal stromal cells isolated from umbilical cord. Cell Transplant 21(8):1711-1726

Grady RM, Merlie JP, Sanes JR (1997) Subtle neuromuscular defects in utrophin-deficient mice. J Cell Biol 136(4):871-882

Grivennikov IA (2008) Embryonic stem cells and the problem of directed differentiation. Biochemistry (Mosc) 73(13):1438-1452

Guan K, Rohwedel J, Wobus AM (1999) Embryonic stem cell differentiation models: cardiogenesis, myogenesis, neurogenesis, epithelial and vascular smooth muscle cell differentiation in vitro. Cytotechnology 30(1-3):211-226

Hart AH, Hartley L, Sourris K, Stadler ES, Li R, Stanley EG, Tam PP, Elefanty AG, Robb L (2002) Mixl1 is required for axial mesendoderm morphogenesis and patterning in the murine embryo. Development 129(15):3597-3608

Hasty P, Bradley A, Morris JH, Edmondson DG, Venuti JM, Olson EN, Klein WH (1993) Muscle deficiency and neonatal death in mice with a targeted mutation in the myogenin gene. Nature 364(6437):501-506

Himeda CL, Barro MV, Emerson CP Jr (2013) Pax3 synergizes with Gli2 and Zic1 in transactivating the Myf5 epaxial somite enhancer. Dev Biol 383(1):7-14

Hosoyama T, McGivern JV, Van Dyke JM, Ebert AD, Suzuki M (2014) Derivation of myogenic progenitors directly from human pluripotent stem cells using a sphere-based culture. Stem Cells Transl Med 3(5):564-574

Huelsken J, Vogel R, Brinkmann V, Erdmann B, Birchmeier C, Birchmeier W (2000) Requirement for beta-catenin in anteriorposterior axis formation in mice. J Cell Biol 148(3):567-578

Hwang Y, Suk S, Lin S, Tierney M, Du B, Seo T, Mitchell A, Sacco A, Varghese S (2013) Directed in vitro myogenesis of human embryonic stem cells and their in vivo engraftment. PLoS One 8(8):e72023

Imberti B, Monti M, Casiraghi F (2015) Pluripotent stem cells and tolerance induction in organ transplantation. Curr Opin Organ Transplant 20(1):86-93

Kahan BW, Ephrussi B (1970) Developmental potentialities of clonal in vitro cultures of mouse testicular teratoma. J Natl Cancer Inst 44(5):1015-1036

Kassar-Duchossoy L, Gayraud-Morel B, Gomes D, Rocancourt D, Buckingham M, Shinin V, Tajbakhsh S (2004) Mrf4 determines skeletal muscle identity in Myf5: Myod double-mutant mice. Nature 431(7007):466-471

Kassar-Duchossoy L, Giacone E, Gayraud-Morel B, Jory A, Gomes D, Tajbakhsh S (2005) Pax3/Pax7 mark a novel population of primitive myogenic cells during development. Genes Dev 19(12):1426-1431

Kazuki Y, Hiratsuka M, Takiguchi M, Osaki M, Kajitani N, Hoshiya H, Hiramatsu K, Yoshino T, Kazuki K, Ishihara C et al (2010) Complete genetic correction of ips cells from Duchenne muscular dystrophy. Mol Ther 18(2):386-393

Kennedy KA, Porter T, Mehta V, Ryan SD, Price F, Peshdary V, Karamboulas C, Savage J, Drysdale TA, Li SC et al (2009) Retinoic acid enhances skeletal muscle progenitor formation and bypasses inhibition by bone morphogenetic protein 4 but not dominant negative beta-catenin. BMC Biol 7:67

Kimbrel EA, Lanza R (2015) Hope for regenerative treatments: toward safe transplantation of human pluripotent stem-cell-based therapies. Regen Med 10(2):99-102

Klimanskaya I, Chung Y, Becker S, Lu SJ, Lanza R (2006) Human embryonic stem cell lines derived from single blastomeres. Nature 444(7118):481-485 
Kuang S, Kuroda K, Le Grand F, Rudnicki MA (2007) Asymmetric self-renewal and commitment of satellite stem cells in muscle. Cell 129(5):999-1010

Lagha M, Kormish JD, Rocancourt D, Manceau M, Epstein JA, Zaret KS, Relaix F, Buckingham ME (2008) Pax3 regulation of FGF signaling affects the progression of embryonic progenitor cells into the myogenic program. Genes Dev 22(13):1828-1837

Leahy A, Xiong JW, Kuhnert F, Stuhlmann H (1999) Use of developmental marker genes to define temporal and spatial patterns of differentiation during embryoid body formation. J Exp Zool 284(1):67-81

L'Honore A, Ouimette JF, Lavertu-Jolin M, Drouin J (2010) Pitx2 defines alternate pathways acting through MyoD during limb and somitic myogenesis. Development 137(22):3847-3856

Lin T, Wu S (2015) Reprogramming with small molecules instead of exogenous transcription factors. Stem Cells Int 2015:794632

Liu P, Wakamiya M, Shea MJ, Albrecht U, Behringer RR, Bradley A (1999) Requirement for Wnt3 in vertebrate axis formation. Nat Genet 22(4):361-365

Maffioletti SM, Gerli MF, Ragazzi M, Dastidar S, Benedetti S, Loperfido M, VandenDriessche T, Chuah MK, Tedesco FS (2015) Efficient derivation and inducible differentiation of expandable skeletal myogenic cells from human ES and patient-specific iPS cells. Nat Protoc 10(7):941-958

Mannello F, Tonti GA (2007) Concise review: no breakthroughs for human mesenchymal and embryonic stem cell culture: conditioned medium, feeder layer, or feeder-free; medium with fetal calf serum, human serum, or enriched plasma; serum-free, serum replacement nonconditioned medium, or ad hoc formula? All that glitters is not gold! Stem Cells 25(7):1603-1609

Martin GR (1981) Isolation of a pluripotent cell line from early mouse embryos cultured in medium conditioned by teratocarcinoma stem cells. Proc Natl Acad Sci USA 78(12):7634-7638

Mizuno Y, Chang H, Umeda K, Niwa A, Iwasa T, Awaya T, Fukada S, Yamamoto H, Yamanaka S, Nakahata T et al (2010) Generation of skeletal muscle stem/progenitor cells from murine induced pluripotent stem cells. Faseb J 24(7):2245-2253

Montarras D, Morgan J, Collins C, Relaix F, Zaffran S, Cumano A, Partridge T, Buckingham M (2005) Direct isolation of satellite cells for skeletal muscle regeneration. Science 309(5743):2064-2067

Moraczewski J, Archacka K, Brzoska E, Ciemerych MA, Grabowska I, Janczyk-Ilach K, Streminska W, Zimowska M (2008) From planarians to mammals - the many faces of regeneration. Int $\mathrm{J}$ Dev Biol 52(2-3):219-227

Murry CE, Keller G (2008) Differentiation of embryonic stem cells to clinically relevant populations: lessons from embryonic development. Cell 132(4):661-680

Nabeshima Y, Hanaoka K, Hayasaka M, Esumi E, Li S, Nonaka I, Nabeshima Y (1993) Myogenin gene disruption results in perinatal lethality because of severe muscle defect. Nature 364(6437):532-535

Osafune K, Caron L, Borowiak M, Martinez RJ, Fitz-Gerald CS, Sato Y, Cowan CA, Chien KR, Melton DA (2008) Marked differences in differentiation propensity among human embryonic stem cell lines. Nat Biotechnol 26(3):313-315

Pagliuca FW, Millman JR, Gurtler M, Segel M, Van Dervort A, Ryu JH, Peterson QP, Greiner D, Melton DA (2014) Generation of functional human pancreatic beta cells in vitro. Cell 159(2): 428-439

Partridge TA, Morgan JE (2014) Multiple insights from myogenic cell transplants. Hum Gene Ther 25(5):404-405

Pereira LA, Wong MS, Mossman AK, Sourris K, Janes ME, Knezevic K, Hirst CE, Lim SM, Pimanda JE, Stanley EG et al (2012) Pdgfralpha and Flk1 are direct target genes of Mixl1 in differentiating embryonic stem cells. Stem Cell Res 8(2): $165-179$
Petropoulos H, Skerjanc IS (2002) Beta-catenin is essential and sufficient for skeletal myogenesis in P19 cells. J Biol Chem 277(18):15393-15399

Pourquie O, Coltey M, Breant C, Le Douarin NM (1995) Control of somite patterning by signals from the lateral plate. Proc Natl Acad Sci USA 92(8):3219-3223

Rao PK, Kumar RM, Farkhondeh M, Baskerville S, Lodish HF (2006) Myogenic factors that regulate expression of muscle-specific microRNAs. Proc Natl Acad Sci USA 103(23):8721-8726

Reijntjes S, Stricker S, Mankoo BS (2007) A comparative analysis of Meox 1 and Meox2 in the developing somites and limbs of the chick embryo. Int J Dev Biol 51(8):753-759

Relaix F, Rocancourt D, Mansouri A, Buckingham M (2004) Divergent functions of murine Pax3 and Pax7 in limb muscle development. Genes Dev 18(9):1088-1105

Relaix F, Rocancourt D, Mansouri A, Buckingham M (2005) A Pax3/ Pax7-dependent population of skeletal muscle progenitor cells. Nature 435(7044):948-953

Rios AC, Serralbo O, Salgado D, Marcelle C (2011) Neural crest regulates myogenesis through the transient activation of NOTCH. Nature 473(7348):532-535

Rohwedel J, Maltsev V, Bober E, Arnold HH, Hescheler J, Wobus AM (1994) Muscle cell differentiation of embryonic stem cells reflects myogenesis in vivo: developmentally regulated expression of myogenic determination genes and functional expression of ionic currents. Dev Biol 164(1):87-101

Rosenthal MD, Wishnow RM, Sato GH (1970) In vitro growth and differetiation of clonal populations of multipotential mouse clls derived from a transplantable testicular teratocarcinoma. J Natl Cancer Inst 44(5):1001-1014

Rossi CA, Pozzobon M, Ditadi A, Archacka K, Gastaldello A, Sanna M, Franzin C, Malerba A, Milan G, Cananzi M et al (2010) Clonal characterization of rat muscle satellite cells: proliferation, metabolism and differentiation define an intrinsic heterogeneity. PLoS One 5(1):e8523

Rudnicki MA, Schnegelsberg PN, Stead RH, Braun T, Arnold HH, Jaenisch R (1993) MyoD or Myf-5 is required for the formation of skeletal muscle. Cell 75(7):1351-1359

Ryan T, Liu J, Chu A, Wang L, Blais A, Skerjanc IS (2012) Retinoic acid enhances skeletal myogenesis in human embryonic stem cells by expanding the premyogenic progenitor population. Stem Cell Rev 8(2):482-493

Sakurai H, Era T, Jakt LM, Okada M, Nakai S, Nishikawa S, Nishikawa S (2006) In vitro modeling of paraxial and lateral mesoderm differentiation reveals early reversibility. Stem Cells 24(3):575-586

Sakurai H, Inami Y, Tamamura Y, Yoshikai T, Sehara-Fujisawa A, Isobe K (2009) Bidirectional induction toward paraxial mesodermal derivatives from mouse ES cells in chemically defined medium. Stem Cell Res 3(2-3):157-169

Sakurai H, Sakaguchi Y, Shoji E, Nishino T, Maki I, Sakai H, Hanaoka K, Kakizuka A, Sehara-Fujisawa A (2012) In vitro modeling of paraxial mesodermal progenitors derived from induced pluripotent stem cells. PLoS One 7(10):e47078

Sato T, Rocancourt D, Marques L, Thorsteinsdottir S, Buckingham M (2010) A Pax3/Dmrt2/Myf5 regulatory cascade functions at the onset of myogenesis. PLoS Genet 6(4):e1000897

Savage J, Voronova A, Mehta V, Sendi-Mukasa F, Skerjanc IS (2010) Canonical Wnt signaling regulates Foxc1/2 expression in P19 cells. Differentiation 79(1):31-40

Scharner J, Zammit PS (2011) The muscle satellite cell at 50: the formative years. Skelet Muscle 1(1):28

Schwartz SD, Hubschman JP, Heilwell G, Franco-Cardenas V, Pan CK, Ostrick RM, Mickunas E, Gay R, Klimanskaya I, Lanza R (2012) Embryonic stem cell trials for macular degeneration: a preliminary report. Lancet 379(9817):713-720 
Seki T, Fukuda K (2015) Methods of induced pluripotent stem cells for clinical application. World J Stem Cells 7(1):116-125

Shelton M, Metz J, Liu J, Carpenedo RL, Demers SP, Stanford WL, Skerjanc IS (2014) Derivation and expansion of PAX7-positive muscle progenitors from human and mouse embryonic stem cells. Stem Cell Rep 3(3):516-529

Shoji E, Woltjen K, Sakurai H (2015) Directed myogenic differentiation of human induced pluripotent stem cells. Methods Mol Biol

Sicinski P, Geng Y, Ryder-Cook AS, Barnard EA, Darlison MG, Barnard PJ (1989) The molecular basis of muscular dystrophy in the mdx mouse: a point mutation. Science 244(4912):1578-1580

Sirbu IO, Duester G (2006) Retinoic-acid signalling in node ectoderm and posterior neural plate directs left-right patterning of somitic mesoderm. Nat Cell Biol 8(3):271-277

Sonnemann KJ, Heun-Johnson H, Turner AJ, Baltgalvis KA, Lowe DA, Ervasti JM (2009) Functional substitution by TAT-utrophin in dystrophin-deficient mice. PLoS Med 6(5):e1000083

Suwinska A, Ciemerych MA (2011) Factors regulating pluripotency and differentiation in early mammalian embryos and embryoderived stem cells. Vitam Horm 87:1-37

Sweetman D, Goljanek K, Rathjen T, Oustanina S, Braun T, Dalmay T, Munsterberg A (2008) Specific requirements of MRFs for the expression of muscle specific microRNAs, miR-1, miR-206 and miR-133. Dev Biol 321(2):491-499

Tajbakhsh S, Rocancourt D, Cossu G, Buckingham M (1997) Redefining the genetic hierarchies controlling skeletal myogenesis: Pax-3 and Myf-5 act upstream of MyoD. Cell 89(1):127-138

Takahashi K, Yamanaka S (2006) Induction of pluripotent stem cells from mouse embryonic and adult fibroblast cultures by defined factors. Cell 126(4):663-676

Takahashi K, Tanabe K, Ohnuki M, Narita M, Ichisaka T, Tomoda K, Yamanaka S (2007) Induction of pluripotent stem cells from adult human fibroblasts by defined factors. Cell 131(5):861-872

Tanaka A, Woltjen K, Miyake K, Hotta A, Ikeya M, Yamamoto T, Nishino T, Shoji E, Sehara-Fujisawa A, Manabe Y et al (2013) Efficient and reproducible myogenic differentiation from human iPS cells: prospects for modeling Miyoshi Myopathy in vitro. PLoS One 8(4):e61540

Tarkowski AK (1998) Mouse chimaeras revisited: recollections and reflections. Int J Dev Biol 42(7):903-908

Tedesco FS, Gerli MF, Perani L, Benedetti S, Ungaro F, Cassano M, Antonini S, Tagliafico E, Artusi V, Longa E et al (2012) Transplantation of genetically corrected human iPSC-derived progenitors in mice with limb-girdle muscular dystrophy. Sci Transl Med 4(140):140-189

Torrente Y, Belicchi M, Sampaolesi M, Pisati F, Meregalli M, D’Antona G, Tonlorenzi R, Porretti L, Gavina M, Mamchaoui K et al (2004) Human circulating $\mathrm{AC} 133(+)$ stem cells restore dystrophin expression and ameliorate function in dystrophic skeletal muscle. J Clin Investig 114(2):182-195

Torres J, Prieto J, Durupt FC, Broad S, Watt FM (2012) Efficient differentiation of embryonic stem cells into mesodermal precursors by BMP, retinoic acid and Notch signalling. PLoS One 7(4):e36405

Udagawa N, Takahashi N, Akatsu T, Sasaki T, Yamaguchi A, Kodama H, Martin TJ, Suda T (1989) The bone marrow-derived stromal cell lines MC3T3-G2/PA6 and ST2 support osteoclastlike cell differentiation in cocultures with mouse spleen cells. Endocrinology 125(4):1805-1813

Unger C, Skottman H, Blomberg P, Dilber MS, Hovatta O (2008) Good manufacturing practice and clinical-grade human embryonic stem cell lines. Hum Mol Genet 17:48-53

Vasyutina E, Stebler J, Brand-Saberi B, Schulz S, Raz E, Birchmeier C (2005) CXCR4 and Gab1 cooperate to control the development of migrating muscle progenitor cells. Genes Dev 19(18): $2187-2198$

Venuti JM, Morris JH, Vivian JL, Olson EN, Klein WH (1995) Myogenin is required for late but not early aspects of myogenesis during mouse development. J Cell Biol 128(4):563-576

Vieira NM, Brandalise V, Zucconi E, Jazedje T, Secco M, Nunes VA, Strauss BE, Vainzof M, Zatz M (2008) Human multipotent adipose-derived stem cells restore dystrophin expression of Duchenne skeletal-muscle cells in vitro. Biol Cell 100(4):231-241

Walsh FS, Ritter MA (1981) Surface antigen differentiation during human myogenesis in culture. Nature 289(5793):60-64

Weintraub H, Tapscott SJ, Davis RL, Thayer MJ, Adam MA, Lassar AB, Miller AD (1989) Activation of muscle-specific genes in pigment, nerve, fat, liver, and fibroblast cell lines by forced expression of MyoD. Proc Natl Acad Sci USA 86(14):5434-5438

Williams BA, Ordahl CP (1994) Pax-3 expression in segmental mesoderm marks early stages in myogenic cell specification. Development 120(4):785-796

Wong J, Mehta V, Voronova A, Coutu J, Ryan T, Shelton M, Skerjanc IS (2013) beta-catenin is essential for efficient in vitro premyogenic mesoderm formation but can be partially compensated by retinoic acid signalling. PLoS One 8(2):e57501

Wu D, Pan W (2010) GSK3: a multifaceted kinase in Wnt signaling. Trends Biochem Sci 35(3):161-168

Wu J, Okamura D, Li M, Suzuki K, Luo C, Ma L, He Y, Li Z, Benner C, Tamura I et al (2015) An alternative pluripotent state confers interspecies chimaeric competency. Nature 521(7552):316-321

$\mathrm{Xu}$ C, Tabebordbar M, Iovino S, Ciarlo C, Liu J, Castiglioni A, Price E, Liu M, Barton ER, Kahn CR et al (2013) A zebrafish embryo culture system defines factors that promote vertebrate myogenesis across species. Cell 155(4):909-921

Yablonka-Reuveni Z (2011) The skeletal muscle satellite cell: still young and fascinating at 50. J Histochem Cytochem 59(12): 1041-1059

Yant SR, Wu X, Huang Y, Garrison B, Burgess SM, Kay MA (2005) High-resolution genome-wide mapping of transposon integration in mammals. Mol Cell Biol 25(6):2085-2094

Zhao T, Zhang ZN, Rong Z, Xu Y (2011) Immunogenicity of induced pluripotent stem cells. Nature 474(7350):212-215

Zhao T, Zhang ZN, Westenskow PD, Todorova D, Hu Z, Lin T, Rong Z, Kim J, He J, Wang M et al (2015) Humanized mice reveal differential immunogenicity of cells derived from autologous induced pluripotent stem cells. Cell Stem Cell 17(3):353-359

Zheng JK, Wang Y, Karandikar A, Wang Q, Gai H, Liu AL, Peng C, Sheng HZ (2006) Skeletal myogenesis by human embryonic stem cells. Cell Res 16(8):713-722 